\title{
Implant Protected Occlusion
}

\author{
Yogeshwari Swaminathan ${ }^{1}$, Gururaj Rao ${ }^{2}$ \\ ${ }^{1}$ (Intern (BDS), Saveetha Dental College \& Hospital, Chennai, India) \\ 2 (MDS, Department of Prosthodontics, Saveetha Dental College \& Hospital, Chennai, India)
}

\begin{abstract}
Implant protected occlusion is a very important criteria to obtain an improved longevity of both the dental implant and the prosthesis. It is an occlusal scheme which reduces the force at the crestal bone and the implant interface. This concept was proposed by Dr. Carl E. Misch. Implant protected occlusion helps in reducing the noxious load and to maintain the implant load within the physiological limits of individualized occlusion. Occlusal overload will lead to biomechanical complications like early implant failure, early crestal bone lost, intermediate to late implant failure, screw loosening, uncemented restoration, component failure, porcelain fracture, prosthesis fracture and periimplant disease.
\end{abstract}

Keywords: Dental implants, implant occlusion, implant protected occlusion, implant longevity, biomechanical complication

\section{Introduction}

Implant treatment has become the treatment of choice and the most desirable treatment option for replacing missing teeth in partially as well as completely edentulous patient. Dental implants have different biological and biomechanical characteristics compared to natural tooth. One of the most important criteria for implant success is implant occlusion.

Implant protected occlusion is very essential as it provides the maximum intercuspation during clenching force and also reduces occlusal load on implant, which helps in protecting the implants. This concept was proposed by Misch and Bidez in 1994 [1]. Implant protected occlusion is an occlusal plan which was designed to provide an improved longevity of both the implant as well as the prosthesis [1]. Occlusal overload leads to biological complications like peri-implant infection [2] and mechanical complications like screw loosening or fracture, prosthesis fracture and implant fracture [3]. The primary difference between a dental implant and a natural tooth is, dental implants are osteointergrated without periodontal ligament therefore there is no shock absorbing function [4]. Besides that, crestal bone acts as a fulcrum when there is occlusal overload which again leads to biological and mechanical complication.

Rangert et al has reported that the clinical success and longevity of dental implants can be achieved by biomechanically controlled occlusion [5]. Consequently, the imperative factor in implant prosthodontics deals with principles of implant protected occlusion for implant selection, implant placement and the prosthetic phase of the treatment [6].

\section{What Is An Ideal Occlusion}

According to GPT, occlusion is defined as any contact between the incising or masticating surface of the maxillary or mandibular teeth. Ideal occlusion provides function, which is efficient mastication and good esthetics without creating physiologic abnormalities. Five important concept of ideal occlusion were described by Dawson in 1974 [7]. The 5 concepts are as follows:

1. Centric relation

Definition of centric relation (GPT) : The maxillomandibular relationship in which the condyles articulate with the thinnest avascular portion of their respected disks with the complex in the anteriorposterior position against the shape of the articular eminencies. The position is independent of tooth contact. This position is clinically discernible when the mandible is directed superior and anteriorly. It is restricted to a purely rotary movement about the transverse horizontal axis.

2. Anterior guidance must be in harmony with the border movements of the envelope of function.

3. Disclusion of all the posterior teeth in protrusive movements.

4. Disclusion of all the posterior teeth on the balancing side.

5. Non interference of all posterior teeth on the working side with either the lateral anterior guidance or the border movements of the condyles.

Every individual has different occlusal pattern, however appropriate pattern can be found based on Dawsons criteria. A clinical trial and a conceptual theory have been reported by Pameijer et al in 1983 about 3 types of occlusion which explains the ideal occlusal schemes [5]. They are balanced occlusion, group function occlusion and canine protected occlusion $[5,7]$. 


\section{Balanced occlusion}

Defined as the simultaneous contacting of the maxillary and mandibular teeth on the right and left and in the posterior and the anterior occlusal areas in centric an acentric position developed to lessen or limit tipping or rotating of the denture bases in relation to the supporting structures (GPT). Balance occlusion is absent in natural dentition. In bilateral balanced occlusion, all teeth comes into contact during excursion therefore it is primarily used in complete denture fabrication [8]. Balanced occlusion can be further classified into 4 types:-
1.1. Unilateral balanced occlusion
1.2 Bilateral balanced occlusion
1.3 Protrusive balanced occlusion
1.4 Lateral balanced occlusion

\section{Group Function Occlusion}

Group Function occlusion is also known as unilateral balanced occlusion. It is seen on the occlusal surface of teeth on one side, when they occlude simultaneously with a smooth uninterrupted glide. The group function on working side distributes the occlusal load [7]. Absence of contacts on non working side prevents those teeth from being subjected to the destructive. This destruction was first observed by Schuyler in 1959 [9]. A study reported by Beyron et al shows that, group function occlusion prevents the excessive wear of the centric holding cusp thus helps in maintenance of occlusion [10].

\section{Canine protected occlusion}

It is also known as mutually protected occlusion or organic occlusion. During lateral or protrusive movements, maxillary and mandibular anterior teeth, guides the mandible in such a way that, there is no posterior occlusal contact. This leads to absences of frictional wear. This occlusion is mutually protective because the posterior teeth protect the anterior teeth at centric relation; the incisors protect the canine and posteriors in protrusion while the canines protect the incisors and posterior teeth during lateral movements [7]. This is solely based on the canine as the key element of occlusion avoiding heavy lateral pressures on posterior teeth [11].

\section{Implant Protected Occlusion}

As mentioned earlier, one of the most important criteria for implant success is implant occlusion. A poor occlusal scheme increases mechanical stresses and strains at the crestal bone for which the crestal bone acts as a fulcrum when there is an occlusal overload. This leads to biological and mechanical complications [12]. Consequences of biomechanical overloads are early implant failure, early crestal bone lost, intermediate to late implant failure [5,13], screw loosening [5], uncemented restoration, component failure, porcelain fracture, prosthesis fracture [5] and periimplant disease [13]. To overcome this problem, to reduce noxious occlusal load and to establish a consistent occlusal philosophy, implant protected occlusal was proposed by Dr. Carl E. Misch which was previously presented as medial positioned lingualized occlusion [1]. Implant-protected occlusion concept addresses several conditions to minimize overload on bone-implant interfaces and implant prostheses which in turn maintains implant load within the physiological limit [7]. Factors influencing implant protected occlusion are shown in table 1 (1).

TABLE 1

IMPLANT PROTECTED OCCLUSION

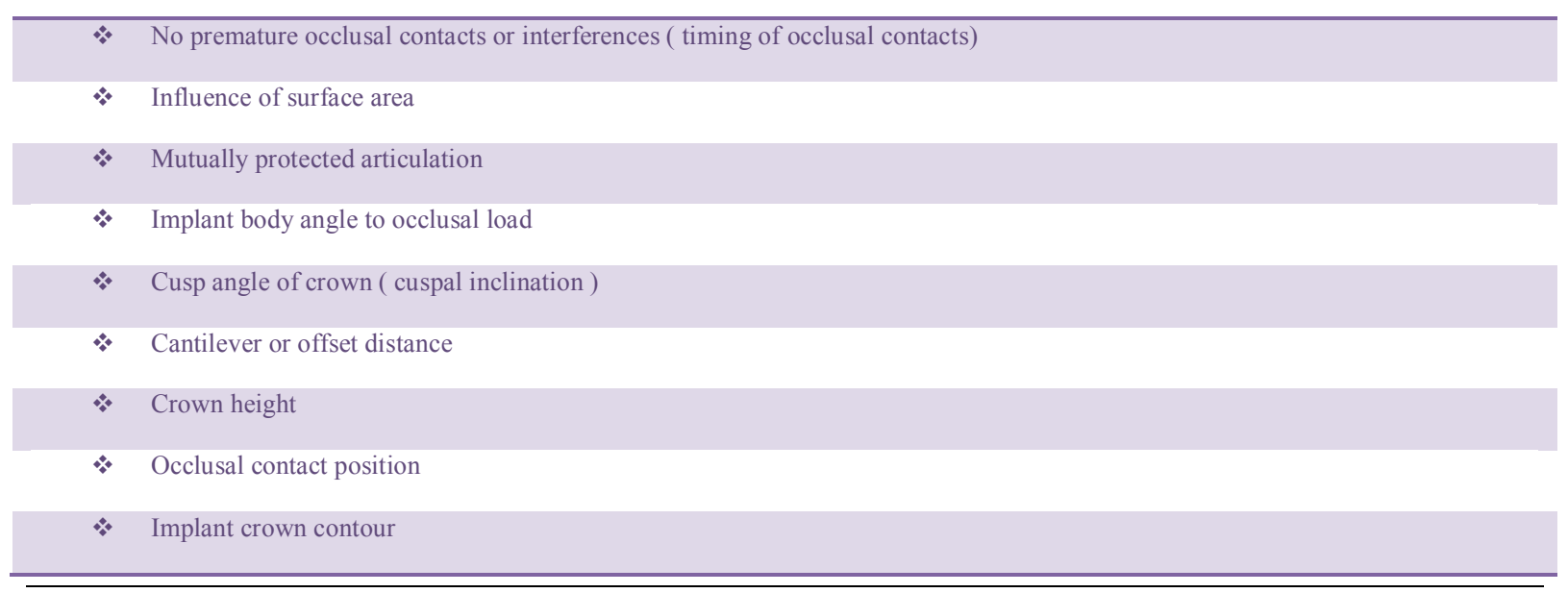




\section{No premature occlusal contact}

During maximum intercuspation, no occlusal contact should be premature. This is based on:

1.1 Natural teeth and implant occlusion

1.2 Timing of occlusal contact

Occlusal prematurity between maximum intercuspation and centric relation occlusion should be taken into consideration especially on an implant supported prostheses. This is because, non-mobile implants bear the entire load of the prosthesis when it comes in contact with the mobile natural teeth, hence during the occlusal adjustment between implants and natural teeth, premature occlusal contacts on the implants can occur as the natural teeth can move away from the centric during function [13].

Miyata et al has reported an animal study, which demonstrates excessive force during premature contact, causing marginal bone lost and osteointegration failure where monkeys with different heights of premature contact were used in this study. Their results proposed that, the more the premature contact on the implant prostheses, the more the crestal bone loss [15]. Besides that, Isidor F also reported a study using monkeys stating that; excessive occlusal overload during pre mature contact causes severe crestal bone resorption and loss of osseointegration [16]. Movement patterns of the natural tooth and the implant movements are shown in table $2[13,15]$.

TABLE 2

Movement patterns of natural teeth and implant movement $(\mu \mathrm{m})$ under loading $(1.36-2.27 \mathrm{~kg})$

\begin{tabular}{|c|c|c|}
\hline VERTICAL DIRECTION & NATURAL TEETH & IMPLANTS \\
\hline Initial tooth movements & $8-28$ & 0 \\
\hline Secondary tooth movement & $3-5$ & $3-5$ \\
\hline
\end{tabular}

Occlusal adjustment can be done by using a thin articulating paper which is less than $25 \mu \mathrm{m}$ to evaluate the centric relation of the occlusal contact. This is done to relieve the implant crown which leads to heavier contact on the adjacent natural tooth. A greater occlusal force is then applied to the articulating paper, establishing equal contact regions on both the implant-supported crowns and natural teeth. Tooth might not return to its original position for several hours after application of a heavy occlusal force. Following this, light forces on adjacent natural teeth are first equilibrated. Occlusal adjustment of implants and teeth in the opposing arch should also be compensated for the primary tooth movement [13].

\section{Influence of surface area}

Sufficient surface area is required to withstand the load transmitted to the prosthesis therefore when an implant of decreased surface area, subjected to increased load in magnitude, direction or duration, the stress and strain in the interfacial tissue will increase. This can be minimized by placing additional implants in the region of concern, ridge augmentation, reduce crown height or by increasing the implant width [17, 18]. Bidez et al have reported a study showing that, forces distributed over 3 abutments results in less stress on the crestal bone compared to 2 abutments [19].

\section{Mutually protected articlulation}

When the natural canines are present, during excursions it allows the teeth to distribute horizontal load and also the posterior tooth to disocclude. This concept is known as canine guidance or mutually protected articulation. However, there should be no contact on the implant crown during excursion to the opposing side and also during protrusion [11]. The anterior guidance of implant prosthesis with anterior implant should be shallow. This is because, the steeper the incisal guidance the greater the force on the anterior implants [20]. Weinberg et al have reported a study stating, every 10- degree change in the angle of disclusion, there is a $30 \%$ difference in the load. For example, if the incisal guidance is 20 degrees, 100 psi is put on the implant [20].

\section{Cusp angle of crown}

Natural dentition has steep cuspal inclination whereas in denture teeth, the cuspal inclination given is $30 \%$. Cusp inclination has been found to produce a high level of torque. For every $10^{\circ}$ increase in cusp inclination, there is an approximately 30\% increase in torque [13]. Weinberg et al in 1995 have reported a study regarding the torque of a gold screw, abutment screw, and implant. They have concluded that, the cuspal inclination produces the most torque, followed by maxillary horizontal implant offset, while implant inclination and apical implant offset produce minimal torque [20]. Kaukinen JA et al have reported a study stating, when 
the cuspal angle becomes greater, it could incise food more efficiently, however as the angle of the cusp increases, stress also increases leading to angled load to the crestal bone [21] hence it gives no advantage but increases the risk. Occlusal contact over an implant crown should be on a flat surface perpendicular to implant body. This is achieved by increasing 2 to $3 \mathrm{~mm}$ of the width of the central groove in the posterior implant crowns and the opposing cusp is recontoured to occlude the central fossa directly over the implant body [22].

\section{Implant body angle to occlusal load}

There can be different impact on the bone and implant interface based on the direction of the load applied even if it's of same magnitude of force, however implant is mainly designed for long axis load [23]. A study was reported by Binderman in 1970, where 50 endosteal implant designs were assessed and found that all the design sustained lesser under a long axis load [24]. The greater the angle of load to the implant long axis, the greater the compressive, tensile and shear stresses which leads to bone loss and unsuccessful bone re growth $[25,26]$.

\section{Crown height}

Implant crown height is often greater than the natural anatomical crown. As the implant crown height becomes greater, the crestal moment with any lateral component of force also becomes greater [27]. Therefore any harmful effect of any feebly selected cusp angle, angled implant body, or angled load to the crown will be magnified by the crown height measurements [22].

\section{Cantilever}

Cantilevers with unfavourable crown or implant ratio, increase the amount of stress to the implant [22]. These can further lead to peri implant bone loss and prosthesis failure [27, 28]. The magnitude of load obtained by the implants is approximately proportional to the length of the cantilevers but it also varies with the implant number, spacing, and location [29,30]. Long cantilevers are correlated with increase crestal bone lost in a clinical report by Lundquist et al in 1988 [27].

\section{Occlusal contact position}

Occlusal contact position determines the direction of force especially during parafunctional activity [22]. In different theories, the number of occlusal contact varies. Occlusal theory by Peter K Thomas suggest that there should be tripod contact on each occluding cusp, on each marginal ridge and central fossa with 18 and 15 individual occlusal contacts on a mandibular and maxillary molars [31] whereas, the other oclusal contact scheme indicates that, number of occlusal contact for molars can be reduced.

\section{Implant crown contour}

In maxilla, the edentulous ridge resorbs gradually in the medial direction whereas in posterior mandible, the resorption occurs in lingual direction. Center of implant is placed in the center of the edentulous ridge because the ridge resorps lingually with resorption hence the implant is mostly not kept under the buccal cusp tip but near the central fossa or more lingually, under the lingual cusp of the natural tooth. The size of the implant body which is the buccolingual dimension is smaller than the natural tooth [22].

\section{Occlusal material}

Occlusal material fracture is one of the most common complications of implant restoration [32] therefore consideration of the occlusal material restoration is very essential for each patient. Occlusal material may be evaluated by esthetic, impact force, static load, chewing efficiency, fracture, wear, interarch space requirement, and accuracy of casting [1]. The factors influencing the occlusal material are shown in table 3 [1].

TABLE 3

\begin{tabular}{|c|c|c|c|}
\hline & PORCELAIN & GOLD & RESIN \\
\hline ESTHETICS & + & - & + \\
\hline IMPACT FORCE & - & + & + \\
\hline STATIC LOAD & + & + & + \\
\hline CHEWING EFFICIENCY & + & + & - \\
\hline FRACTURE & - & + & - \\
\hline WEAR & - & + & - \\
\hline INTERARCH SPACE & - & + & - \\
\hline
\end{tabular}

Favourable $:[+]$

Unfavourable : [-] 


\section{Difference Between Dental Implant And Natural Tooth}

Differences between dental implant and natural tooth is shown in table 4 [33].

TABLE 4

\begin{tabular}{|c|c|}
\hline ТООТН & IMPLANT \\
\hline $\begin{array}{l}\text { Periodontal membrane } \\
\text { longer force duration } \\
\text { distribution of force around tooth } \\
\text { tooth mobility can be related to force } \\
\text { mobility dissipates lateral force } \\
\text { fremitus related to force } \\
\text { radiographic changes related to force (reversible) }\end{array}$ & $\begin{array}{l}\text { Direct bone implant } \\
\text { higher impact force } \\
\text { force primarily to crest } \\
\text { implant is always rigid (mobility is failure) } \\
\text { lateral force increases strain to bone } \\
\text { no fremitus } \\
\text { radiographic changes at crest-bone lost (not reversible) }\end{array}$ \\
\hline $\begin{array}{l}\text { Biomechanical design } \\
\text { * cross section related to direction and amount of stress } \\
\text { elastic modulus similar to bone } \\
\text { * disameter related to force magnitude }\end{array}$ & $\begin{array}{l}\text { Implant design } \\
* \quad \text { round cross section and designed for surgery } \\
\text { elastic modulus } 5 \text { to } 10 \text { times that of cortical bone } \\
\text { diameter related to existing bone }\end{array}$ \\
\hline $\begin{array}{l}\text { Sensory nerve complex in and around the tooth } \\
\text { occlusal trauma induces hyperemia and leads to cold } \\
\text { sensitivity } \\
\text { proprioception (reduce maximum bite force) } \\
\text { less functional bite force }\end{array}$ & $\begin{array}{l}\text { No sensory nerve } \\
\text { no precursor sign of slight occlusal trauma } \\
\text { occlusal awareness of } 2 \text { to } 5 \text { times less (higher maximum } \\
\text { bite force functional) } \\
\text { functional bite force } 4 \text { times higher }\end{array}$ \\
\hline $\begin{array}{l}\text { Occlusal material ( enamel ) } \\
* \quad \text { enamel wears, stress lines, abrasion and pits }\end{array}$ & $\begin{array}{l}\text { Occlusal material (porcelain } \\
* \quad \text { no early sign of force }\end{array}$ \\
\hline $\begin{array}{l}\text { Surrounding bone is cortical bone } \\
\text { resistant to change }\end{array}$ & $\begin{array}{l}\text { Surrounding bone is trabecular (may be fine ) } \\
\text { conductive to change }\end{array}$ \\
\hline
\end{tabular}

\section{Natural Tooth Versus Implant Characteristics Under Load}

Tooth versus implant biomechanic is shown in table 5 [33]

TABLE 5

\begin{tabular}{|c|c|c|}
\hline CRITERION & TOOTH & IMPLANT \\
\hline Connection & PDL & Function ankylosis \\
\hline Impact force & Decreased & Increased \\
\hline Mobility & $\begin{array}{l}\text { Variable } \\
\text { Anterior teeth more than posterior teeth }\end{array}$ & None \\
\hline Movement & Shock breaker affect of PDL & Stressed captured at crest \\
\hline Apical & Intrude quickly $28 \mu \mathrm{m}$ & No initial movements \\
\hline Lateral & 56 to $108 \mu \mathrm{m}$ & 10 to $50 \mu \mathrm{m}$ \\
\hline Diameter & Large & Small \\
\hline Cross section & Not round & Round \\
\hline Modulas of elasticity & With or without cortical bone & 5 to 10 times greater than trabecular bone \\
\hline Signs of hyperemia & Yes & No \\
\hline Orthodontic movements & Yes & No \\
\hline Fremitus & Yes & No \\
\hline Radiographic changes & PDL thickening and cortical bone & No \\
\hline Progressive loading & Since childhood & Shorter loading period \\
\hline Wear & Enamel wear facets, localized fatigue and & Minimal wear, screw loosening, stress and \\
\hline
\end{tabular}




\begin{tabular}{|c|c|c|}
\hline & $\begin{array}{l}\text { stress fracture, cervical abraction and pitting } \\
\text { on oacclusal cusp }\end{array}$ & $\begin{array}{l}\text { fracture of prosthetic components or implant } \\
\text { body }\end{array}$ \\
\hline Tactile sensitivity & High & Low \\
\hline $\begin{array}{l}\text { Occlusal awareness } \\
\text { (proprioception) }\end{array}$ & High detection of premature contacts & $\begin{array}{l}\text { Low ( higher loads to premature occlusal } \\
\text { contact) }\end{array}$ \\
\hline
\end{tabular}

\section{Conclusion}

The objectives of implant protected occlusion is to reduce noxious occlusal load on the bone implant interface and implant prosthesis, to establish a consistent occlusal philosophy, to maintain implant load within the physiological limits of individualized occlusion, and finally to provide long-term stability of implants and implant prostheses. Therefore principles of implant protected occlusion are one of the very important criteria for implant as well as the prosthesis longevity.

\section{References}

[1] Misch C E, Bidez M W, Implant-protected occlusion: a biomechanical rationale, Compendium, 15, $1994,1330-1344$.

[2] Tonetti, M. \& Schmid, J, Pathogenesis of implant failures. Periodontology,4, 1995, 127-138.

[3] Schwarz M S, Mechanical complications of dental implants, Clinical Oral Implants Research, 11 (Suppl.),2000, 156-158.

[4] Schulte W, Implants and the periodontium, International Dental Journal, 45, 1995, 16-26.

[5] Kim Y, Oh T-J, Misch CE, Wang H-L, Occlusal considerations in implant therapy: clinical guidelines with biomechanical rationale, Clin. Oral Impl, 16, 2005, 26-35.

[6] Y H Ismail, N Yacoub, Occlusal consideration in implant prosthodontics, Dental News, 5(3), 1998, 19-24.

[7] Shantanu J, Mohit K, Mukund K, Ramandeep D, Occlusion and occlusal consideration in implantology, Indian J of Dental Advancements, 2(1), 2010, 125-130.

[8] Stuart CE, Articulation of human teeth. In: Collum, B.B. \& Stuart, C.E., eds. A research report, 91-123.

[9] Schuyler C H, Considerations of occlusion in fixed partial dentures, Dental Clinics of North America, 37,1959, 175-185

[10] Beyron, H.L, Optimal occlusion. Dental Clinics of North America,37, 1969, 537-554.

[11] D'Amico A, The canine teeth: normal functional relation of the natural teeth of man, Journal of South California Dental Association, 26, 1958, 1-7.

[12] Misch CE, Early crestal bone lost etiology and its effect on treatment planning for implants, Postgrad Dent,3, $1995,3-17$.

[13] Y Y Chen, C L Kuan, Y B Wang, Implant occlusion: biomechanical considerations for implant supported prostheses, $J$ Dent Sci, 3(2), 2008, $65-74$.

[14] Parfitt GJ, Measurement of the physiological mobility of individual teeth in an axial direction, J Dent Res, 39, 1960, 608-618.

[15] Miyata T, Kobayashi Y, Araki H, Ohto T, Shin K, The influence of controlled occlusal overload on peri-implant tissue. Part 3: A histologic study in monkeys, Int J Oral Maxillofac Implants, 15, 2000, 425-431.

[16] Isidor F, Loss of osseointegration caused by occlusal load of oral implants. A clinical and radiographic study in monkeys, Clin Oral Implants Res, 7, 1996, 143-152.

[17] Rangert B, Krogh PH, Langer B, et al, Bending overload and implant fracture: a retrospective clinical analysis, Int $J$ of Oral Maxillofac Implants, 7, 1995, 40-44.

[18] Gunne J, Jemt T, Linden B. Implant treatment in partially edentulous patients: a report on prostheses after 3 years, Int J Oral Maxillofac Implant, 7, 1994, 143-148.

[19] Bidez MW, Misch CE, The biomechanics of interimplant spacing. Proceedings of the fourth international congress of implants and biomaterials in stomatology, Charleston, SC, May 1990.

[20] Weinberg LA, Kruger G, A comparison of implant prostheses loading for clinical variables, Int J Prosthodont,8, 1995 , $421-433$.

[21] Kaukinen JA, Edge MJ, Lang BR, The influence of occlusal design on simulated masticatory forces transferred to implant retained prostheses and supporting bone, J Prosthet Dent,76, 1996, 50-55.

[22] Misch CE et al, Dental implant prosthetics. Elsevier's Health Sciences Right Department, Philadelphia USA, 2005.

[23] Bidez MW, Misch CE, Force transfer in implant dentistry: basic concept and principle, Oral Implantol, 18, 1992, 264-274.

[24] Binderman I.NIH- grant study on 2 dimentional FEA study of 54 implant body designs, 1973 (personal communication).

[25] Misch CE. Three dimentional finite element analysis of two plate form neck design, master's thesis, university of Pittsburgh, 1989.

[26] Clelland NL, Lee JK, Bimbenet OC et al, A three dimentional finite element stress analysis of angled abutments for an implant placed in an anterior maxilla, J Prosthodont, 4, 1995, 95-100.

[27] Lindquist LW, Rockler B, Garlsson GE, Bone resorption around fixtures in edentulous patients treated with mandibular fixed tissue-integrated prostheses, J Prosthet Dent, 59,1988, 59-63.

[28] Shackleton JL, Carr L, Slabbert JC, Becker PJ, Survival of fixed implant-supported prostheses related to cantilever lengths, $J$ Prosthet Dent, 71, 1994, 23-26.

[29] Falk H, Lurell L, Lundgren D, Occlusal interferences and cantilever joint joint stress in implant supported prostheses occlusing with complete dentures, Int J Oral Maxillofac Implants, 5, 1990, 70 -77.

[30] Wang S, Hobkirk JA, Load distribution on implants with cantilevered superstructures: in vitro pilot study, Implant Dent, 5, 1996, $36-42$.

[31] Thomas P K, Sylabbus for full mouth waxing technique for rehabilitation tooth to tooth cusp-fossa concept of organic occlusion, (ed 2), San Francisco, University of Callifonia school of Dentistry, Los Angeles, 1967.

[32] Goodacre CJ, Khan JK,Rungeharassaeng K, Clinical complication of osteointergrated impants, J Prosthet Dent, 81, 1991, 537552 .

[33] Smitha AJ, Vidyashree N, Sanjna N, Anoop G, Occlusal principles and considerations for the osseointegrated prosthesis, IOSR Journal of Dental and Medical Sciences, 5(3), 2013, 47-54. 